\title{
CONCOMITANT COMPLEX REGIONAL PAIN SYNDROME AND BEHÇET'S DISEASE: A CASE REPORT
}

Maria de Lourdes Castro de Oliveira Figueirôa ${ }^{1}$, Gustavo Luiz Behrens Pinto ${ }^{1}$, Renata Borges de Lima ${ }^{1}$, Viviane Leal Novais Alisson Regis de Santana ${ }^{1}$, Mariana Oliveira Miranda ${ }^{1}$, Victor Pereira Mattos ${ }^{1, \star}$

1.Universidade Federal da Bahia, Salvador (BA), Brazil.

*Corresponding author: lourdinhafigueiroa@hotmail.com

\section{BACKGROUND}

Complex regional pain syndrome (CRPS) is a rare condition, usually triggered by a traumatic event, characterized by extreme regional pain associated with sensorimotor, vasomotor, sudomotor, and trophic changes in the affected site. It affects women more frequently, with an average age between 50-70 years. The disease can be further divided into CRPS- 1 and CRPS-2, differentiated by the absence or presence of peripheral nerve damage, respectively. It may be clinically diagnosed based on Budapest criteria with a broad differential diagnosis, including thrombosis, local infections, and rheumatic diseases. Its pathophysiology is not fully defined, and the increasing search for an effective treatment is an object of medical concern. The authors present a case of a patient diagnosed with Behçet's disease (BD), who developed CRPS type 1 in her right hand.

\section{CASE REPORT}

A 56-year-old female was diagnosed with BD 13 years ago with mucocutaneous, ocular, articular, and neurological manifestations. She has been in disease remission using cyclosporine $3 \mathrm{mg} / \mathrm{kg} / \mathrm{day}$ when she developed pain, diffuse edema, and hair thinning in her right hand (Figure 1) after trauma 7 months ago. After excluding thrombotic causes, treatment with prednisone $40 \mathrm{mg} / \mathrm{day}$ and pregabalin $75 \mathrm{mg} /$ day was initiated, and she had clinical improvement. However, during corticoid reduction, her symptoms recurred, requiring reintroduction of the previous dose of prednisone and intravenous infusion of pamidronate $60 \mathrm{mg}$, with complete resolution of the symptoms.

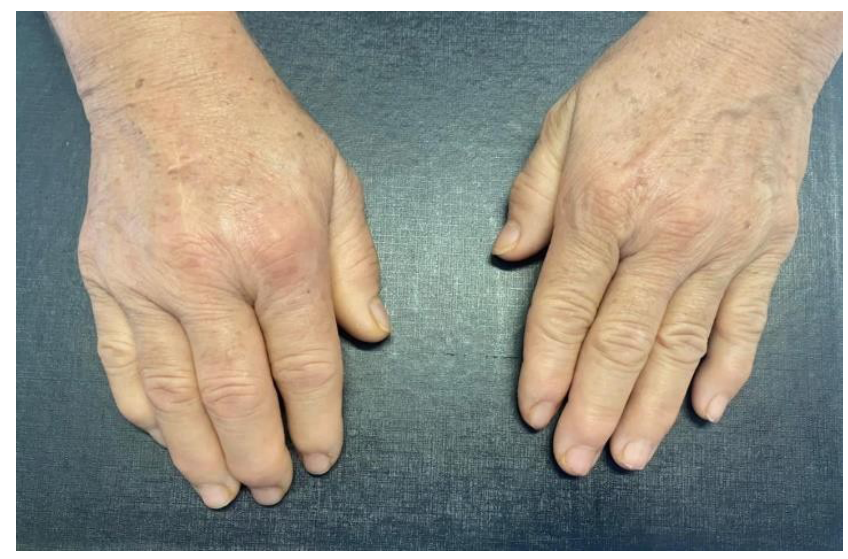

Figure 1. Diffuse edema of the right upper limb.

\section{CONCLUSION}

Both CRPS and BD are uncommon in clinical practice. In addition, the concomitance of these conditions is infrequent and can make the diagnostic approach to CRPS even more challenging. In our patient, control of the pain was obtained with corticosteroids and bisphosphonate, which may alert the rheumatologists to a correct diagnosis and an effective and less invasive treatment.

\section{KEYWORDS}

Dystrophies, Reflex sympathetic, Type I, CRPS, Behçet's disease. 